\title{
OUTCOMES OF CARBOTAXOL IN CARCINOSARCOMA: A RETROSPECTIVE STUDY AT THE BRAZILIAN NATIONAL CANCER INSTITUTE (INCA)
}

$\underline{\text { L. Albuquerque }}^{1}$, J. Lope da Silva² , A. Letícia Gasparotto ${ }^{3}$, B. Regina Lima de Aguiar ${ }^{4}$, D. de Sousa Barros Rodrigues ${ }^{5}$, T. Costa Farias ${ }^{6}$, A. Cristina de Melo².

${ }^{1}$ Universidade Federal Fluminense, Faculdade de Medicina, Rio de Janeiro, Brazil; ${ }^{2}$ Instituto Nacional de Câncer, Divisão de Pesquisa Clinica e Desenvolvimento Tecnológico, Rio de Janeiro, Brazil; ${ }^{3}$ Universidade Federal do Paraná, Faculdade de Medicina, Paraná, Brazil; ${ }^{4}$ Universidade de Brasilia, Departamento de

Enfermagem, Distrito Federal, Brazil; ${ }^{5}$ Universidade Federal da Paraíba, Programa de pós-graduação em Fonoaudiologia, João Pessoa, Brazil; ${ }^{6}$ Universidade Federal de Campina Grande, Faculdade de Medicina, Paraíba, Brazil.

\section{Objectives}

Uterine carcinosarcomas (UC) are rare metaplastic tumors with dual composition of mesenchymal and epithelial elements, seen as a good example of epithelial-mesenchymal transition (EMT). The current study evaluated the efficacy and safety of Carbotaxol (CT) as adjuvant and first-line (1L) palliative treatment for women with carcinosarcoma.

\section{Methods}

This retrospective cohort of patients (pts) with UC treated with 3qw Carbotaxol at INCA between January 2012 and January 2017 assessed overall survival (OS), disease-free survival (DFS), progression-free survival (PFS), response rate (RR), and tolerability. All analyses were performed with the SPSS software, version 18.0.

\section{Results}

Table 1 - Patient and treatment characteristics $(\mathrm{N}=48)$

\begin{tabular}{lc} 
Age & \\
Median & 66,1 \\
Range & $59,5-70,4$ \\
\hline FIGO stage & \\
\hline I & $10(20,8 \%)$ \\
II & $10(20,8 \%)$ \\
III & $21(43,8 \%)$ \\
IV & $7(14,6 \%)$ \\
\hline
\end{tabular}

\section{Surgery characteristics}

\begin{tabular}{l|l}
\hline TAH + BSO & $6(12,5 \%)$ \\
\hline $\begin{array}{l}\text { TAH + BSO + } \\
\text { lymph (with or }\end{array}$ & $26(54,2 \%)$ \\
without om) & \\
Other & $16(33,3 \%)$
\end{tabular}

Status of margin
R0 $42(87,5 \%)$
Chemotherapy characteristics

Adjuvant

chemotherapy $\quad 26(54,2 \%)$

(AC)

Recurrence after

AC

First line paliative

chemotherapy

Carbotaxol /

Doxorubicin

$14(53,8 \%)$

$21(43,8 \%)$

$18(85,7 \%) / 3$

$(14,3 \%)$

Response rate for metastatic disease

Partial response $\quad 2(9,5 \%)$

Stable disease $\quad 6(28,6 \%)$

Progressive

disease

$12(57,1 \%)$

Radiological

evaluation not

avaiable

$1(4,8 \%)$

Total abdominal histerectomy - TAH; Bilateral salpingo-oophorectomy - BSO;

Lymphadenectomy - lymph; Omentectomy - om

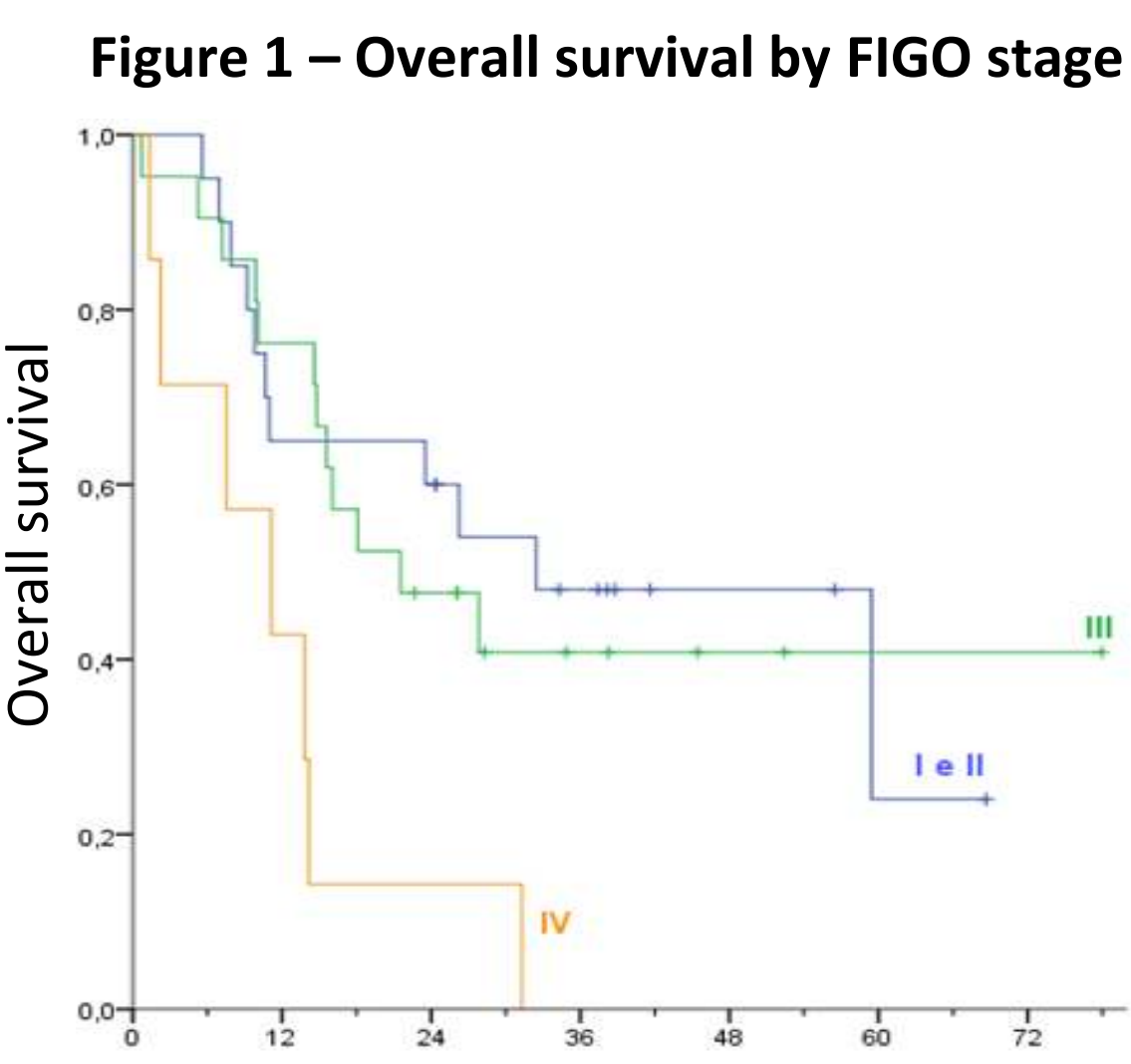

Follow-up (months) $\quad N=48$

\begin{tabular}{|c|c|c|}
\hline & Median & Cl 95\% \\
\hline I e II & 32,5 & $9,8-55,1$ \\
\hline III & 21,5 & $6,2-36,9$ \\
\hline IV & 11,1 & $9-34,1$ \\
\hline
\end{tabular}

Figure 3 - Progression-free survival among pts treated with $1 \mathrm{~L}$

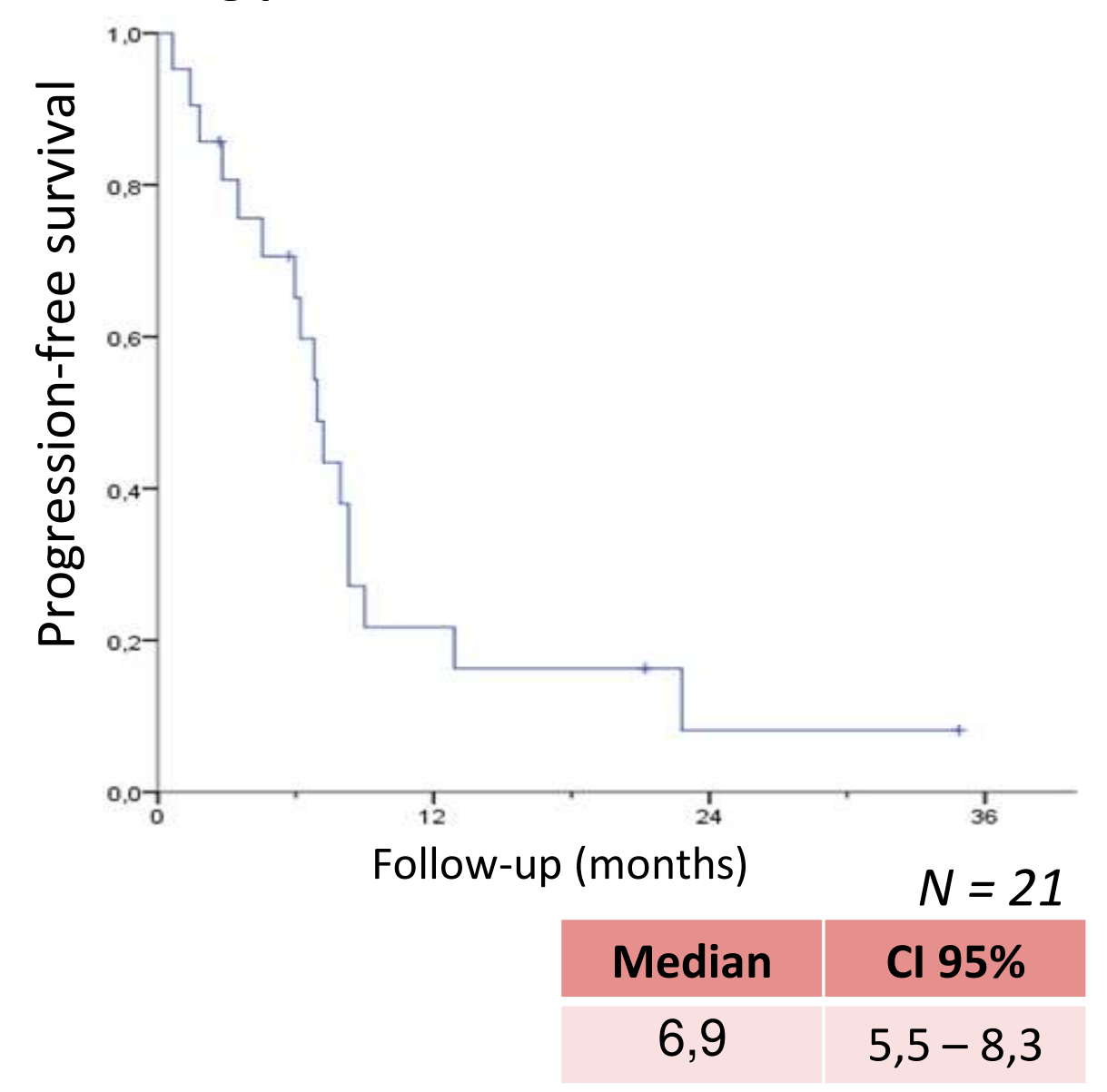

Figure 2 - Disease free survival among pts treated with AC

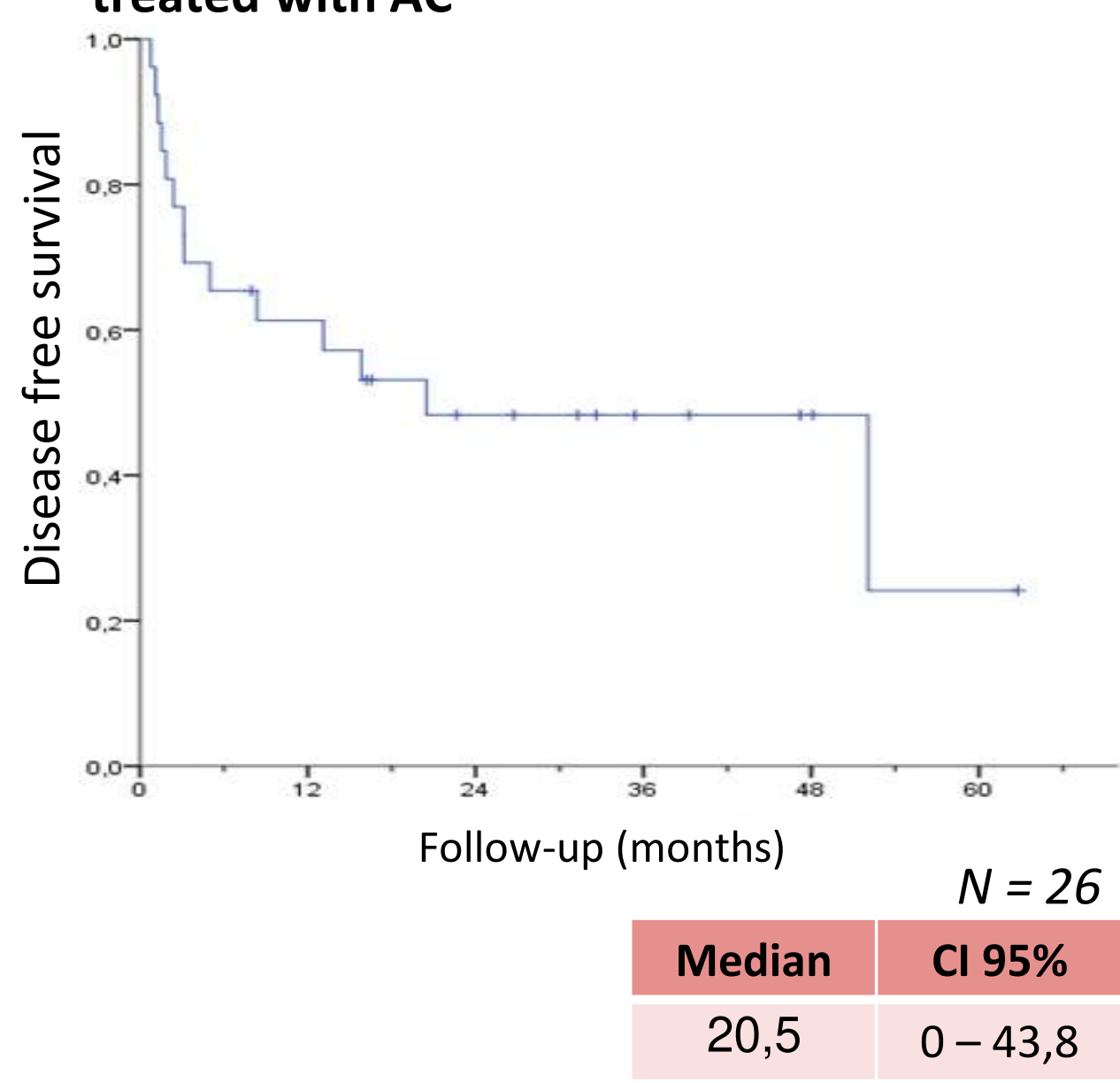

Figure 4 - Overall survival among pts treated with $1 \mathrm{~L}$

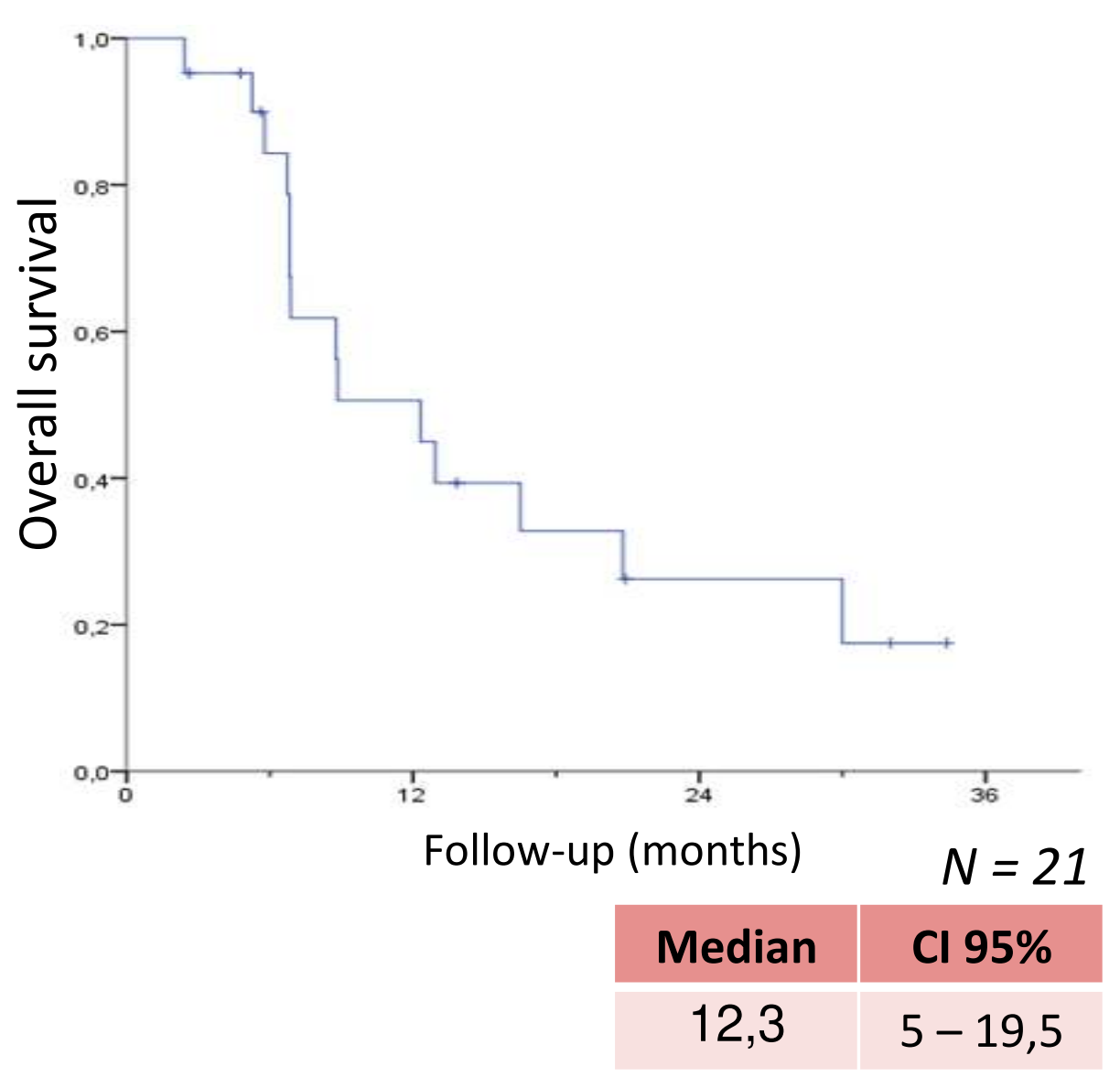

\section{Conclusions}

The combination of carboplatin and paclitaxel has been shown to be effective and safe for the treatment of UC. Staging was confirmed as a strong prognostic factor. The adverse events were manageable and there were no chemo-related deaths. The results were quite similar to those previously reported by multicenter studies. 